\title{
ESTIMACIÓN DE LA VOLATILIDAD DE LOS FONDOS DE INVERS IÓN ABIERTOS EN BOLIVIA
}

\section{Alejandro Vargas Sanchez}

\section{RESUMEN}

En el presente documento se desarrollan conceptos y aplicaciones relacionadas con modelos de econometría financiera, el objetivo principal fue la determinación del nivel de volatilidad de los rendimientos reportados por los Fondos de Inversión Abiertos en Bolivia. Mediante la aplicación de los modelos GARCH, MMEP y de Volatilidad Estocástica, se pudo determinar la volatilidad condicional e incondicional. Por otro lado, mediante el uso de los modelos GJR y EGARCH se evaluó la presencia de asimetría en la volatilidad de los rendimientos, finalmente se realizó la estimación del modelo GARCH-M para establecer el nivel de rentabilidad ajustada al riesgo. Los resultados obtenidos mediante el análisis de 28 series de tiempo en un periodo de 5 años, permitieron establecer una línea base para medir el nivel de riesgo existente en la rentabilidad alcanzada por los Fondos de Inversión Abiertos.

Palabras clave: Volatilidad, Fondos de Inversión, GARCH, GJR, EGARCH, GARCH-M, Riesgo.

DOI: $10.23881 /$ idupbo.017.2-2e 